This item was submitted to Loughborough's Research Repository by the author.

Items in Figshare are protected by copyright, with all rights reserved, unless otherwise indicated.

\title{
Seismic response of subsystems in irregular buildings
}

PLEASE CITE THE PUBLISHED VERSION

http://dx.doi.org/10.1680/jstbu.15.00032

PUBLISHER

(C) ICE Publishing

VERSION

NA (Not Applicable or Unknown)

LICENCE

CC BY-NC-ND 4.0

REPOSITORY RECORD

Kasinos, Stavros, Alessandro Palmeri, and Mariateresa Lombardo. 2019. "Seismic Response of Subsystems in Irregular Buildings". figshare. https://hdl.handle.net/2134/20993. 


\section{Seismic response of subsystems in irregular buildings}

\section{Stavros Kasinos MEng}

PhD Candidate, School of Civil and Building Engineering, Loughborough University, Loughborough, UK

Alessandro Palmeri Dott Ing, PhD

Senior Lecturer in Structural Engineering, School of Civil and Building

Engineering, Loughborough University, Loughborough, UK

(corresponding author: a.palmeri@lboro.ac.uk)
Mariateresa Lombardo Dott Ing, PhD

Senior Lecturer in Structural Engineering, School of Civil and Building

Engineering, Loughborough University, Loughborough, UK

The component-mode synthesis method is applied to investigate the seismic response of secondary subsystems multiconnected to primary structures with irregularities. The proposed approach is more accurate than the cascade approximation, which is often used in the design practice, as the primary-secondary dynamic interaction is considered through the modes of vibration of the two components. The results of parametric analyses on a representative case study reveal similar trends in the displacements of the two components for mass irregularities in elevation, while stiffness irregularities in plan can result in significant torsional motion in both components, with the effects in terms of absolute accelerations being in general larger than those associated with the lateral drifts. This suggests that dynamic analyses with the component-mode synthesis method are particularly indicated for the seismic assessment of acceleration-sensitive secondary subsystems.

\section{Notation}

$\mathbf{c}, \mathbf{c}_{\mathrm{S}}, \mathbf{c}_{\mathrm{P}}, \mathbf{c}_{\mathrm{SP}}$ and $\mathbf{c}_{\mathrm{PP}}$ reduced damping matrices in modal subspace

$g$

$\mathbf{I}_{r}$

$\mathbf{K}, \mathbf{K}_{\mathrm{P}}, \mathbf{K}_{\mathrm{S}}, \mathbf{K}_{\mathrm{SP}}, \mathbf{K}_{\mathrm{PP}}$

$\mathbf{k}, \mathbf{k}_{\mathrm{PP}}$

$\mathbf{M}, \mathbf{M}_{\mathrm{p}}, \mathbf{M}_{\mathrm{S}}$

$\mathbf{m}, \mathbf{m}_{\mathrm{PP}}, \mathbf{m}_{\mathrm{SP}}$

$m, m_{\mathrm{P}}, m_{\mathrm{S}}$

$n, n_{\mathrm{P}}, n_{\mathrm{S}}$

$\mathbf{O}_{r \times s}$

$\mathbf{p}_{\mathrm{P}}, \mathbf{p}_{\mathrm{S}}, \mathbf{p}_{\mathrm{PP}}$ $\mathbf{q}(t), \mathbf{q}_{\mathbf{P}}(t), \mathbf{q}_{\mathbf{s}}(t)$

$T_{\mathrm{P}}, T_{\mathrm{S}}$

$\mathbf{u}(t), \mathbf{u}_{\mathrm{P}}(t), \mathbf{u}_{\mathrm{S}}(t)$

$\ddot{\boldsymbol{u}}_{\mathrm{g}}(t)$

$\alpha_{\mathrm{M}}, \alpha_{\mathrm{K}}$

$\Gamma$

$\zeta_{\mathrm{P}}, \zeta_{\mathrm{S}}$

$\kappa$

$\mu, \mu_{i}$

$\rho$

$\tau, \tau_{\mathrm{P}}, \tau_{\mathrm{S}}$

$\boldsymbol{\Phi}, \boldsymbol{\Phi}_{\mathrm{P}}, \boldsymbol{\Phi}_{\mathrm{S}}$

$\boldsymbol{\Psi}_{\mathrm{SP}}$

$\boldsymbol{\Omega}, \boldsymbol{\Omega}_{\mathrm{P}}, \boldsymbol{\Omega}_{\mathrm{S}}$ eccentricity

reduced influence vector of seismic incidence

$r$-dimensional identity matrix

full stiffness matrices

reduced stiffness matrices

full mass matrices

reduced mass matrices

number of modal coordinates

number of degrees of freedom (DoF)

$r \times s$ zero matrix

arrays of modal participation factors

arrays collecting modal coordinates

periods of vibration

arrays collecting DoF

ground acceleration

proportionality coefficients for mass and stiffness in Rayleigh damping model

modal transformation matrices

viscous damping ratios

eccentricity ratio

mass ratios

radius of gyration of floor plan

vectors of seismic incidence

modal matrices

primary-secondary modal coupling matrix

diagonal spectral matrices
$\omega_{\mathrm{I}}, \omega_{\mathrm{II}}$

circular frequencies assumed for average viscous damping ratios in Rayleigh damping model

\section{Introduction}

In the context of earthquake engineering, secondary (S) subsystems are components or contents of a building that are not part of the primary (P) load-bearing structure. Examples include partition walls, cladding and mechanical, plumbing, electrical and auxiliary equipment, which can be modelled as single- or multi-degree-of-freedom dynamic systems, either linear or non-linear, singly or multiply connected to the $\mathrm{P}$ structure. Their seismic analysis and design is a topic of broad engineering interest because damage to the $\mathrm{S}$ components can cause injury or death, as well as interruption of services, which in turn can lead to further human and economic losses (Villaverde, 2009). S subsystems can be highly sensitive to accelerations and inter-storey drifts, and their seismic performance is influenced by the primary-secondary (P-S) dynamic interaction, which in many situations needs to be accounted for (Muscolino and Palmeri, 2013).

The dynamic response of building structures to earthquakes is affected by irregularities in their arrangement, which typically arise from architectural, functional or accidental requirements (e.g. usage variations, inconsistencies in the construction process, damage etc.), either in plan (i.e. asymmetric distributions of mass, stiffness and strength) or in elevation (e.g. due to discontinuities in structural elements or variations in 
occupancy). In fact, irregular buildings tend to exhibit complicated modes of vibration (Shahrooz and Moehle, 1990; Wood, 1992), for example with concentrated deformations in soft storeys or large torsional effects. As a result, they often suffer higher levels of damage than regular structures. This has prompted the imposition of restrictions on various aspects of seismic design in modern building codes, with implications on structural modelling, allowed methods of analysis and behaviour factors.

With regards to vertical mass distribution, Eurocode 8 (BSI, 2004) specifies, for regular buildings, a criterion of no abrupt variations in the mass of individual storeys, without explicitly quantifying what would be an abrupt change. Conversely, other codes dictate that a vertical mass irregularity exists when the mass of a storey exceeds $150 \%$ (ASCE, 2010) or $200 \%$ (BIS, 2002; ICBO, 1997; NBCC, 2010) of the mass of an adjacent storey (however, a roof significantly lighter than the floor below would not be considered as an irregularity). Furthermore, with respect to lateral stiffness, Eurocode 8 requires a regular structure to be approximately symmetrical in plan in two orthogonal axes, with prescriptive limits given on the structural eccentricity orthogonal to the direction of the analysis.

Alongside the development of the above code requirements, several studies have been carried out to examine the seismic response of building structures with irregularities. Valmundsson and Nau (1997) highlighted some inconsistencies in the mass, stiffness and strength criteria of regularity set out by the Uniform Building Code (UBC) (ICBO, 1997). Das and Nau (2003) studied the effects of vertical irregularity for both mass and stiffness, suggesting that the UBC restrictions might be too conservative. Choi (2004) evaluated the seismic response of multi-storey frames and showed that the most severe cause of irregularity was when a change in mass happens at the uppermost floors. Aydin (2007) suggested that the results of an equivalent lateral force procedure tend to overestimate those of time history analyses, independently of the degree of irregularity. More recently, Varadharajan et al. (2014) proposed a single parameter to quantify an irregularity in terms of both magnitude and location, while design code quantification classifies irregularity on the basis of magnitude only.

Tezcan and Alhan (2001) investigated torsionally irregular multi-storey structures by varying the location of shear walls and comparing the equivalent lateral force with dynamic analyses. Ozmen (2004) examined the conditions that cause large torsional effects, while Kumar et al. (2012) quantified the performance of symmetric and asymmetric buildings via pushover analyses. Lavan and De Stefano (2013) and Gokdemir et al. (2013) have recently studied the torsional effects induced by the non-coincidence of the centres of mass and stiffness on the seismic performance of frame structures.
All the studies cited focus on the response analysis of irregular $\mathrm{P}$ structures, without addressing the effects on any S subsystem. However, given their key role in ensuring the serviceability of buildings and the current shift towards performance-based earthquake engineering (fib, 2012), an accurate estimation of the consequences that structural irregularities may have on non-structural components appears to be of key importance.

Motivated by these considerations, the results of a parametric study are presented in this paper. A convenient variant of the component-mode synthesis method (CMS) (Biondi and Muscolino, 2000; Hurty, 1960) is used to quantify the seismic response of an $\mathrm{S}$ subsystem multi-connected to a three-dimensional $\mathrm{P}$ multi-storey moment-resisting frame, with irregularities in terms of both mass distribution in elevation and lateral stiffness in plan. The results of the numerical analyses allow the identification of various trends in terms of relative displacements and absolute accelerations for both types of irregularities, and highlight the need for future research.

\section{Combined P-S system vibration via a component-mode synthesis method (CMS)}

\subsection{Undamped vibration}

Consider the case of an $\mathrm{S}$ subsystem with $n_{\mathrm{S}}$ degrees of freedom (DoF) multiply connected to a $\mathrm{P}$ structure with $n_{\mathrm{P}}$ DoF. Within the linear-elastic range, the undamped seismic motion is ruled by

\section{1. $\mathbf{M} \cdot \ddot{\mathbf{u}}(t)+\mathbf{K} \cdot \mathbf{u}(t)=-\mathbf{M} \cdot \boldsymbol{\tau} \ddot{\boldsymbol{u}}_{\mathrm{g}}(t)$}

where, following the CMS formulation by Biondi and Muscolino (2000), $\mathbf{u}(t)=\left\{\mathbf{u}_{\mathrm{S}}^{\top}(t): \mathbf{u}_{\mathrm{P}}^{\top}(t)\right\}^{\top}$ is the partitioned array collecting the $n \operatorname{DoF}\left(n=n_{\mathrm{S}}+n_{\mathrm{P}}\right)$ of the combined dynamic system, in which $\mathbf{u}_{\mathrm{S}}(t)=\left\{u_{\mathrm{S}, 1}(t), \ldots, u_{\mathrm{S}, n_{\mathrm{S}}}(t)\right\}^{\top}$ and $\mathbf{u}_{\mathrm{P}}(t)=\left\{u_{\mathrm{P}, 1}(t), \ldots, u_{\mathrm{P}, n_{\mathrm{P}}}(t)\right\}^{\top}$ are arrays listing the DoF of the $\mathrm{S}$ and $\mathrm{P}$ components, respectively, and superscript $T$ represents

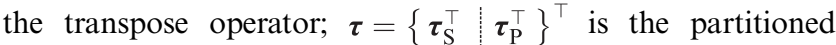
array of seismic incidence; $\ddot{\boldsymbol{u}}_{\mathrm{g}}(t)$ is the ground acceleration and $\mathbf{M}$ and $\mathbf{K}$ are the matrices of mass and elastic stiffness, respectively, which can be partitioned as

2a. $\mathbf{M}=\left[\begin{array}{c:c}\mathbf{M}_{\mathrm{S}} & \mathbf{O}_{n_{\mathrm{S}} \times n_{\mathrm{P}}} \\ \hdashline \mathbf{O}_{n_{\mathrm{P}} \times n_{\mathrm{S}}} & \mathbf{M}_{\mathrm{P}}\end{array}\right]$

2b. $\quad \mathbf{K}=\left[\begin{array}{c:c}\mathbf{K}_{\mathrm{S}} & \mathbf{K}_{\mathrm{SP}} \\ \hdashline \mathbf{K}_{\mathrm{SP}}^{\top} & \mathbf{K}_{\mathrm{P}}+\mathbf{K}_{\mathrm{PP}}\end{array}\right]$

where $\left\{\mathbf{M}_{\mathbf{S}}, \mathbf{K}_{\mathbf{S}}\right\}$ and $\left\{\mathbf{M}_{\mathbf{B}} \mathbf{K}_{\mathbf{P}}\right\}$ are the two pairs of mass and stiffness matrices of the $\mathrm{S}$ and $\mathrm{P}$ subsystems, individually 
considered, in which the $\mathrm{P}$ structure is assumed to be fixed to the ground, while the $\mathrm{S}$ subsystem is also fixed to the support points on $\mathrm{P}$; $\mathbf{O}_{r \times s}$ denotes a zero matrix with $r$ rows and $s$ columns; $\mathbf{K}_{\mathrm{SP}}$ and $\mathbf{K}_{\mathrm{PP}}$ represent the coupling stiffness of the two subsystems and the additional stiffness in the $\mathrm{P}$ substructure due to the presence of the S subsystem, respectively, whose elements only depend on the stiffness of the links used to connect the $\mathrm{P}$ and $\mathrm{S}$ components.

\subsection{Modal coordinate transformation}

The number of DoF in the dynamic analysis can significantly be reduced by projecting the differential equations of motion onto the modal subspaces. This requires the following $n \times m$ transformation of coordinates (Biondi and Muscolino, 2000)

\section{3. $\mathbf{u}(t)=\boldsymbol{\Gamma} \cdot \mathbf{q}(t)$}

in which $\mathbf{q}(t)=\left\{\mathbf{q}_{\mathbf{S}}^{\top}(t): \mathbf{q}_{\mathrm{P}}^{\top}(t)\right\}^{\top}$ is the $m$-dimensional array $\left(m=m_{\mathrm{S}}+m_{\mathrm{P}}\right)$ collecting the modal coordinates of the $\mathrm{P}-\mathrm{S}$ system, where those of the $\mathrm{S}$ subsystem, listed in the array $\mathbf{q}_{\mathbf{S}}(t)=\left\{q_{\mathrm{S}, 1}(t), \ldots, q_{\mathrm{S}, m_{\mathrm{S}}}(t)\right\}^{\top}$, precede those of the $\mathrm{P}$ structure, $\mathbf{q}_{\mathrm{P}}(t)=\left\{q_{\mathrm{P}, 1}(t), \ldots, q_{\mathrm{P}, m_{\mathrm{P}}}(t)\right\}^{\top}$; and $\boldsymbol{\Gamma}$ is a transformation matrix, conveniently assembled as

4. $\Gamma=\left[\begin{array}{c:c}\boldsymbol{\Phi}_{\mathrm{S}} & \boldsymbol{\Psi}_{\mathrm{SP}} \\ \hdashline \mathbf{O}_{n_{\mathrm{P}} \times m_{\mathrm{S}}} & \boldsymbol{\Phi}_{\mathrm{P}}\end{array}\right]$

where $\boldsymbol{\Phi}_{\mathrm{S}}=\left[\phi_{\mathrm{S}, 1} \ldots \phi_{\mathrm{S}, m_{\mathrm{S}}}\right]$ and $\boldsymbol{\Phi}_{\mathrm{P}}=\left[\phi_{\mathrm{P}, 1} \ldots \phi_{\mathrm{P}, m_{\mathrm{P}}}\right]$ are the $n_{\mathrm{S}} \times m_{\mathrm{S}}$ and $n_{\mathrm{P}} \times m_{\mathrm{P}}$ modal matrices for the $\mathrm{S}$ and $\mathrm{P}$ subsystems, respectively, and $\boldsymbol{\Psi}_{\mathrm{SP}}=\left[\psi_{\mathrm{SP}, 1} \ldots \psi_{\mathrm{SP}, m_{\mathrm{S}}}\right]$ is the $n_{\mathrm{S}} \times m_{\mathrm{P}}$ coupling matrix.

The two modal matrices can be obtained by solving two independent real-valued eigenproblems (Muscolino and Palmeri, 2007)

5a. $\quad \mathbf{M}_{\mathrm{S}} \cdot \boldsymbol{\Phi}_{\mathrm{S}} \cdot \boldsymbol{\Omega}_{\mathrm{S}}^{2}=\mathbf{K}_{\mathrm{S}} \cdot \boldsymbol{\Phi}_{\mathrm{S}}$

5b. $\quad \mathbf{M}_{\mathrm{P}} \cdot \boldsymbol{\Phi}_{\mathrm{P}} \cdot \boldsymbol{\Omega}_{\mathrm{P}}^{2}=\mathbf{K}_{\mathrm{P}} \cdot \boldsymbol{\Phi}_{\mathrm{P}}$

with the orthonormal conditions $\boldsymbol{\Phi}_{\mathrm{S}}^{\top} \cdot \mathbf{M}_{\mathrm{S}} \cdot \mathbf{\Phi}_{\mathrm{S}}=\mathbf{I}_{m_{\mathrm{S}}}$ and $\boldsymbol{\Phi}_{\mathrm{P}}^{\top} \cdot \mathbf{M}_{\mathrm{P}} \cdot \boldsymbol{\Phi}_{\mathrm{P}}=\mathbf{I}_{m_{\mathrm{P}}}$. In Equation $5, \boldsymbol{\Omega}_{\mathrm{S}}$ and $\boldsymbol{\Omega}_{\mathrm{P}}$ are the diagonal spectral matrices, listing the modal circular frequencies of $\mathrm{S}$ and $\mathrm{P}$, respectively, and $\mathbf{I} r$ stands for the identity matrix of size $r$.

The coupling matrix can be obtained by solving the matrix equation

6. $\mathbf{K}_{\mathrm{S}} \cdot \boldsymbol{\Psi}_{\mathrm{SP}}=-\mathbf{K}_{\mathrm{SP}} \cdot \boldsymbol{\Phi}_{\mathrm{P}}$
Substituting Equation 3 into Equation 1 and pre-multiplying the result by $\Gamma^{\top}$, the equation of motion in the modal subspaces is ruled by

7. $\mathbf{m} \cdot \ddot{\mathbf{q}}(t)+\mathbf{k} \cdot \mathbf{q}(t)=\boldsymbol{g} \ddot{\boldsymbol{u}}_{\mathrm{g}}(t)$

where $\mathbf{m}$ and $\mathbf{k}$ are the matrices of mass and stiffness and $\boldsymbol{g}$ is the influence vector of seismic incidence in the reduced modal subspace, respectively. These are defined as

8a. $\mathbf{m}=\boldsymbol{\Gamma}^{\top} \cdot \mathbf{M} \cdot \boldsymbol{\Gamma}=\left[\begin{array}{c:c}\mathbf{I}_{m_{\mathrm{S}}} & \mathbf{m}_{\mathrm{SP}} \\ \hdashline \mathbf{m}_{\mathrm{SP}}^{\top} & \mathbf{I}_{m_{\mathrm{P}}}+\mathbf{m}_{\mathrm{PP}}\end{array}\right]$

8b. $\mathbf{k}=\boldsymbol{\Gamma}^{\top} \cdot \mathbf{K} \cdot \boldsymbol{\Gamma}=\left[\begin{array}{c:c}\boldsymbol{\Omega}_{\mathrm{S}}^{2} & \mathbf{O}_{m_{\mathrm{S}} \times m_{\mathrm{P}}} \\ \hdashline \mathbf{O}_{m_{\mathrm{P}} \times m_{\mathrm{S}}} & \boldsymbol{\Omega}_{\mathrm{P}}^{2}+\mathbf{k}_{\mathrm{PP}}\end{array}\right]$

8c. $\quad \boldsymbol{g}=-\boldsymbol{\Gamma}^{\top} \cdot \mathbf{M} \cdot \boldsymbol{\tau}=-\left[\frac{\mathbf{p}_{\mathrm{S}}}{\mathbf{p}_{\mathrm{P}}+\mathbf{p}_{\mathrm{PP}}}\right]$

where $\mathbf{p}_{\mathrm{S}}=\boldsymbol{\Phi}_{\mathrm{S}}^{\top} \cdot \mathbf{M}_{\mathrm{S}} \cdot \boldsymbol{\tau}_{\mathrm{S}}$ and $\mathbf{p}_{\mathrm{P}}=\boldsymbol{\Phi}_{\mathrm{P}}^{\top} \cdot \mathbf{M}_{\mathrm{P}} \cdot \boldsymbol{\tau}_{\mathrm{P}}$ are the two arrays collecting the modal participation factors for $\mathrm{S}$ and $\mathrm{P}$, respectively.

The presence of the $\mathrm{S}$ subsystem affects the mass, stiffness and participation factors of the $\mathrm{P}$ structure through the additional blocks

9a. $\quad \mathbf{m}_{\mathrm{PP}}=\boldsymbol{\Psi}_{\mathrm{SP}}^{\top} \cdot \mathbf{M}_{\mathrm{S}} \cdot \boldsymbol{\Psi}_{\mathrm{SP}}$

9b. $\quad \mathbf{k}_{\mathrm{PP}}=\boldsymbol{\Phi}_{\mathrm{P}}^{\top} \cdot\left[\mathbf{K}_{\mathrm{PP}} \cdot \boldsymbol{\Phi}_{\mathrm{P}}+\mathbf{K}_{\mathrm{SP}}^{\top} \cdot \boldsymbol{\Psi}_{\mathrm{SP}}\right]$

9c. $\quad \mathbf{p}_{\mathrm{PP}}=\boldsymbol{\Psi}_{\mathrm{SP}}^{\top} \cdot \mathbf{M}_{\mathrm{S}} \cdot \boldsymbol{\tau}_{\mathrm{S}}$

Furthermore, the $\mathrm{P}-\mathrm{S}$ coupling is established in the reduced modal space by the out-of-diagonal block $\mathbf{m}_{\mathrm{SP}}$, given by

10. $\mathbf{m}_{\mathrm{SP}}=\boldsymbol{\Phi}_{\mathrm{S}}^{\top} \cdot \mathbf{M}_{\mathrm{S}} \cdot \boldsymbol{\Psi}_{\mathrm{SP}}$

\subsection{Viscous damping matrix}

Without loss of generality, the Rayleigh damping model is adopted in the following for the two subsystems. Accordingly, 
the viscous damping matrix in the reduced modal space can be assembled as

11. $\mathbf{c}=\left[\begin{array}{c:c}\mathbf{c}_{\mathrm{S}} & \mathbf{c}_{\mathrm{SP}} \\ \hdashline \mathbf{c}_{\mathrm{SP}}^{\top} & \mathbf{c}_{\mathrm{P}}+\mathbf{c}_{\mathrm{PP}}\end{array}\right]$

where $\mathbf{c}_{\mathrm{S}}$ and $\mathbf{c}_{\mathrm{P}}$ are the corresponding damping matrices of the $\mathrm{S}$ and $\mathrm{P}$ components individually considered. These are given by

12a. $\quad \mathbf{c}_{\mathrm{S}}=\zeta_{\mathrm{S}}\left[\alpha_{\mathrm{M}} \mathbf{I}_{m_{\mathrm{S}}}+\alpha_{\mathrm{K}} \mathbf{\Omega}_{\mathrm{S}}^{2}\right]$

$12 b$.

$$
\mathbf{c}_{\mathrm{P}}=\zeta_{\mathrm{P}}\left[\alpha_{\mathrm{M}} \mathbf{I}_{m_{\mathrm{P}}}+\alpha_{\mathrm{K}} \boldsymbol{\Omega}_{\mathrm{P}}^{2}\right]
$$

in which $\zeta_{\mathrm{S}}$ and $\zeta_{\mathrm{P}}$ are the viscous damping ratios for $\mathrm{S}$ and $\mathrm{P}$, respectively, while $\alpha_{\mathrm{M}}$ and $\alpha_{\mathrm{K}}$ are the coefficients of proportionality for mass and stiffness, evaluated as:

13a. $\quad \alpha_{\mathrm{M}}=\frac{2 \omega_{\mathrm{I}} \omega_{\mathrm{II}}}{\omega_{\mathrm{I}}+\omega_{\mathrm{II}}} b ; \quad \alpha_{\mathrm{K}}=\frac{2}{\omega_{\mathrm{I}}+\omega_{\mathrm{II}}} b$

13b. $\quad b=\frac{2\left(\omega_{\mathrm{II}}^{2}-\omega_{\mathrm{I}}^{2}\right)}{\omega_{\mathrm{II}}^{2}-\omega_{\mathrm{I}}^{2}+2 \omega_{\mathrm{I}} \omega_{\mathrm{II}} \ln \left(\omega_{\mathrm{II}} / \omega_{\mathrm{I}}\right)}$

where $\left[\omega_{\mathrm{I}}, \omega_{\mathrm{II}}\right]$ is the interval of circular frequencies in which the average values of $\zeta_{\mathrm{S}}$ and $\zeta_{\mathrm{P}}$ are assumed.

Furthermore, the coupling of the two subsystems and the additional damping in the $\mathrm{P}$ substructure are considered through $\mathbf{c}_{\mathrm{SP}}$ and $\mathbf{c}_{\mathrm{PB}}$ respectively, given by

14. $\mathbf{c}_{\mathrm{SP}}=\zeta_{\mathrm{S}} \alpha_{\mathrm{M}} \mathbf{m}_{\mathrm{SP}}$

15. $\mathbf{c}_{\mathrm{PP}}=\zeta_{\mathrm{S}}\left[\alpha_{\mathrm{M}} \mathbf{m}_{\mathrm{PP}}+\alpha_{\mathrm{K}} \mathbf{k}_{\mathrm{PP}}\right]$

The combined response of the P-S system is then ruled by

16. $\mathbf{m} \cdot \ddot{\mathbf{q}}(t)+\mathbf{c} \cdot \dot{\mathbf{q}}(t)+\mathbf{k} \cdot \mathbf{q}(t)=\mathbf{g} \ddot{\boldsymbol{u}}_{\mathrm{g}}(t)$

Notably

Modal frequencies and modal shapes of the coupled P-S dynamic system are the solution of the real-valued eigenproblem

17. $\mathbf{m} \cdot \boldsymbol{\Phi} \cdot \mathbf{\Omega}^{2}=\mathbf{k} \cdot \boldsymbol{\Phi}$
- The blocks of Equations 9, 10, 14 and 15 account for the dynamic feedback between the two components, and neglecting their contribution would lead to the cascaded approximation.

- Any irregularity in the $\mathrm{P}$ structure is accounted for by the modal matrices $\boldsymbol{\Phi}_{\mathrm{P}}$ and $\boldsymbol{\Psi}_{\mathrm{SB}}$ while the presence of the $\mathrm{S}$ attachment can result in further irregularities.

\section{Numerical applications}

In order to canvass the seismic response of coupled P-S systems in the presence of irregularities in the main loadresisting structure, a representative case study was numerically investigated. The results of parametric analyses are presented and discussed in this section.

\subsection{Modelling}

Figure 1(a) shows the P-S combined dynamic system under consideration, which consists of a three-dimensional five-storey moment-resisting frame (P) multiply connected with flexible links to a multi-DoF piping system (S). The floors of the $\mathrm{P}$ frame are assumed to be rigid in their own plane, so as to simulate the presence of slabs. Self-weight and super-dead load are the two sources of mass, which is concentrated at the floor level for the $\mathrm{P}$ structure and uniformly distributed for the $\mathrm{S}$ subsystem. The total masses are $M_{\mathrm{P}}=97.9 \mathrm{Mg}$ and $M_{\mathrm{S}}=0.3 \mathrm{Mg}$ and the resulting $\mathrm{S}-\mathrm{P}$ mass ratio is $\mu=M_{\mathrm{S}} / M_{\mathrm{P}}=0 \cdot 003$, while the axial stiffness of the links is set to $277 \mathrm{MN} / \mathrm{m}$. The fundamental periods of vibration are $T_{\mathrm{P}, 1}=0.421 \mathrm{~s}$ for the $\mathrm{P}$ structure and $T_{\mathrm{S}, 1}=0.484 \mathrm{~s}$ for the $\mathrm{S}$ piping (the latter being fixed to the ground as well as to the points of connection to $\mathrm{P}$ ).

In its reference configuration, the $\mathrm{P}$ frame is doubly symmetrical in plan and has equal storey masses, fully meeting the regularity criteria in plan and elevation, while $\mathrm{S}$ has an unsymmetrical geometry, as depicted in Figure 1(b).

The number of DoF is $n_{\mathrm{P}}=120$ for $\mathrm{P}$ (24 per storey) and $n_{\mathrm{S}}=336$ for $\mathrm{S}$ (where a finer discretisation is required), leading to a total of $n=n_{\mathrm{P}}+n_{\mathrm{S}}=456$ DoF. Only $m=m_{\mathrm{P}}+m_{\mathrm{S}}=6+121=127$ modes $(28 \%)$ were retained in the analysis, so that at least $90 \%$ of the modal mass for each submodel participates in the seismic motion in the direction of interest ( $x$ for all the analyses here), a criterion borrowed from current codes of practice (BSI, 2004).

The reference values of the viscous damping ratios are $\zeta_{\mathrm{P}}=0.05$ and $\zeta_{\mathrm{S}}=0.02$, respectively, while the circular frequencies for the Rayleigh damping model are $\omega_{\mathrm{I}}=1 \mathrm{rad} / \mathrm{s}$ and $\omega_{\text {II }}=100 \mathrm{rad} / \mathrm{s}$, chosen as representative bounds of the energy content of the seismic input and kept constant throughout the analyses.

In order to trigger the $\mathrm{P}-\mathrm{S}$ dynamic interaction for an accelerogram applied along $x$, the seventh mode of the 


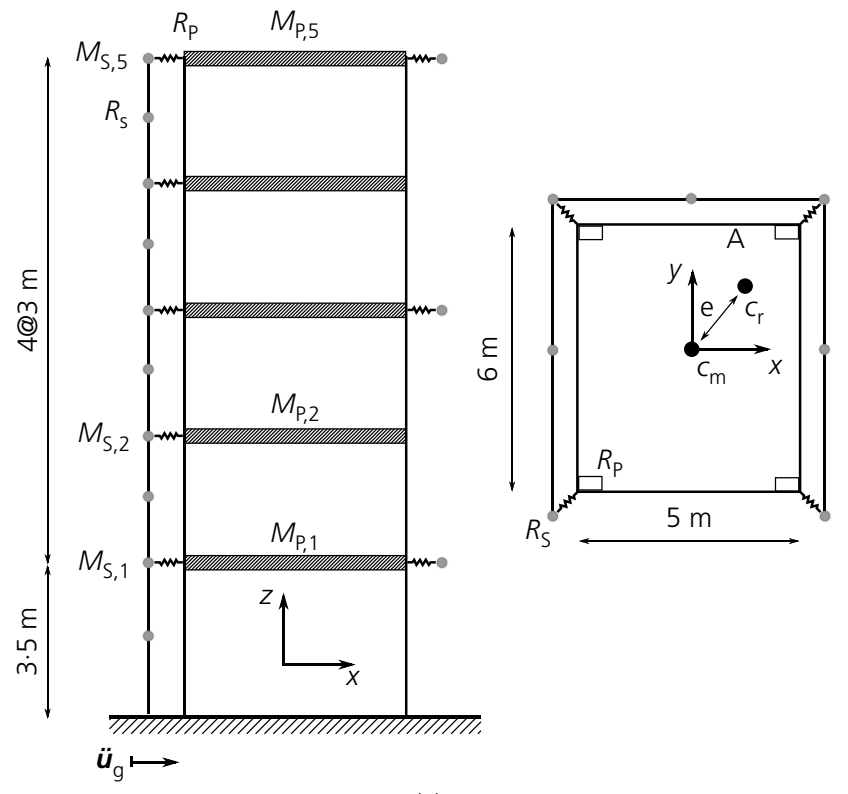

(a)

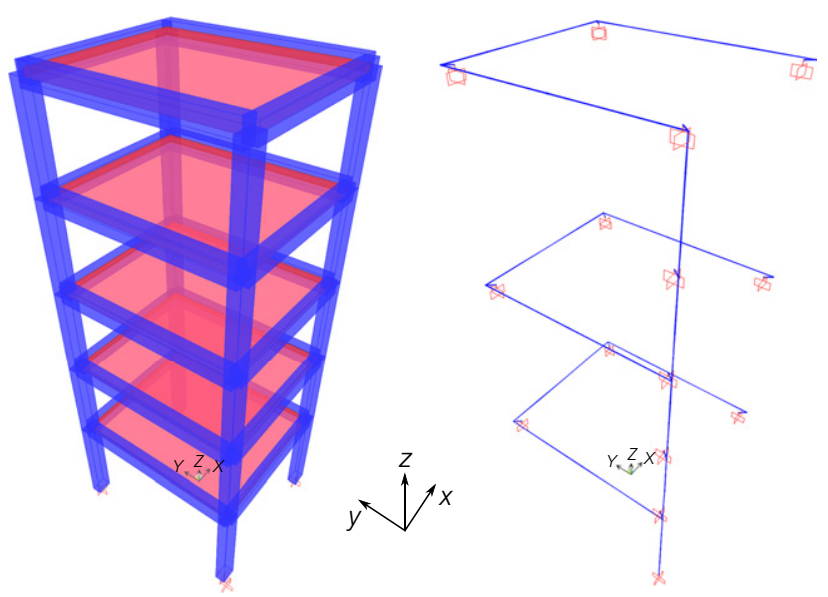

(b)

Figure 1. Primary-secondary case study: specification (a) and base-fixed system configuration (b)

$\mathrm{S}$ piping, with a large participation mass in the direction of interest, was tuned to the second mode of the $\mathrm{P}$ frame, which accounts for about $85 \%$ of $M_{\mathrm{P}}$ in the $x$ direction, so that $T_{\mathrm{P}, 2}=T_{\mathrm{S}, 7}=0 \cdot 385 \mathrm{~s}$.

\subsection{Parametric study}

A series of linear dynamic analyses was carried out using the commercial software Sap2000 (CSI, 2007) to assemble the relevant mass and stiffness matrices and the numerical software Matlab (TMWI, 2013) to implement the CMS variant described in the previous section. The open application programming interface (OAPI) of Sap2000 was used to allow the bidirectional exchange of data with Matlab, including the model updating of the mass and stiffness matrices.

\begin{tabular}{llcc} 
Earthquake & Site/component & $\Delta t: \mathrm{s}$ & PGA: m/s ${ }^{2}$ \\
\hline Imperial valley 1940 & El Centro/180 & 0.01000 & $0.313 \mathrm{~g}$ \\
Erzincan 1992 & Erzincan/N-S & 0.00500 & $0.515 \mathrm{~g}$ \\
Irpinia 1980 & Calitri/270 & 0.00244 & $0.176 \mathrm{~g}$
\end{tabular}

Table 1. Ground motion records

Three recorded accelerograms were used, namely El Centro 1940, Erzincan 1992 and Irpinia 1980 (see Table 1). These records were chosen because of their distinct characteristics (see Cecini and Palmeri, 2015), which allow exploration of the performance of the combined $\mathrm{P}-\mathrm{S}$ system under different loading scenarios and can be used to identify some general trends in the results.

The validity of the CMS was initially confirmed for the reference frame, with a fully regular configuration (Section 3.3). The effects of irregularities in the vertical distribution of the mass were then investigated by increasing in turn the mass of the second, third and fourth storey. Finally, variations in the dynamic response due to stiffness irregularities in plan were studied by varying the stiffness of the corner column, denoted by the letter A in Figure 1(a) (Section 3.4).

The amount of irregularity applied to the P frame was quantified with two dimensionless ratios, namely the mass ratio between two consecutive storeys

18a. $\quad \mu_{i}=\frac{M_{\mathrm{P}, i}}{M_{\mathrm{P}, i-1}} \quad(i=2, \ldots, 5)$

and the eccentricity ratio

18b. $\kappa=\frac{e}{\rho}$

where $e$ is the distance between centre of mass and centre of rigidity $\left(c_{\mathrm{m}}\right.$ and $c_{\mathrm{r}}$, respectively, in Figure 1(a)) and $\rho$ is the radius of gyration of the floor plan.

In order to allow for a fair assessment as well as maintain the $\mathrm{P}-\mathrm{S}$ interaction effects, $M_{\mathrm{P}}$ and $T_{\mathrm{P}, 2}$ were kept constant and the tuning condition $T_{\mathrm{P}, 2}=T_{\mathrm{S}, 7}$ was maintained, irrespective of the level of mass and stiffness irregularity.

According to the principles of performance-based earthquake engineering (fib, 2012), different S components can be sensitive to different engineering demand parameters (EDPs). In the present study, they were selected as the maximum absolute displacements in the $\mathrm{P}$ frame $\left(u_{\mathrm{P}}\right)$, the maximum absolute displacements in the $\mathrm{S}$ piping, relative to the $\mathrm{P}$ frame $\left(u_{\mathrm{S}}^{\mathrm{r}}\right)$ and the maximum absolute accelerations in both $\mathrm{P}$ and $\mathrm{S}$ submodels ( $\ddot{u}_{\mathrm{P}}$ and $\ddot{\boldsymbol{u}}_{\mathrm{S}}$ ). Points $R_{\mathrm{P}}$ and $R_{\mathrm{S}}$ in Figure $1(\mathrm{a})$ identify the 
positions on the $\mathrm{P}$ and $\mathrm{S}$ submodels where the EDPs were calculated.

\subsection{Validation of the CMS}

In order to enable a fair comparison between the CMS (with $m=127$ modes of vibration) and the full dynamic P-S system (with $n=456 \mathrm{DoF}$ ), the same value of viscous damping ratio $\zeta_{\mathrm{P}}=\zeta_{\mathrm{S}}=0.05$ was initially assumed for the two submodels, as this allows use of the Rayleigh damping model for both the full system and the CMS (Equations 12, 14 and 15).

Figure 2 compares the frequency response function (FRF) of a representative degree of freedom in the $\mathrm{S}$ piping (i.e. the $x$ displacement of point $R_{\mathrm{S}}$; see Figure 1(a)), as evaluated for three levels of approximation, namely the full combined system (thick solid line), which can be regarded as the reference solution, the CMS (dotted line) and the cascade approximation,

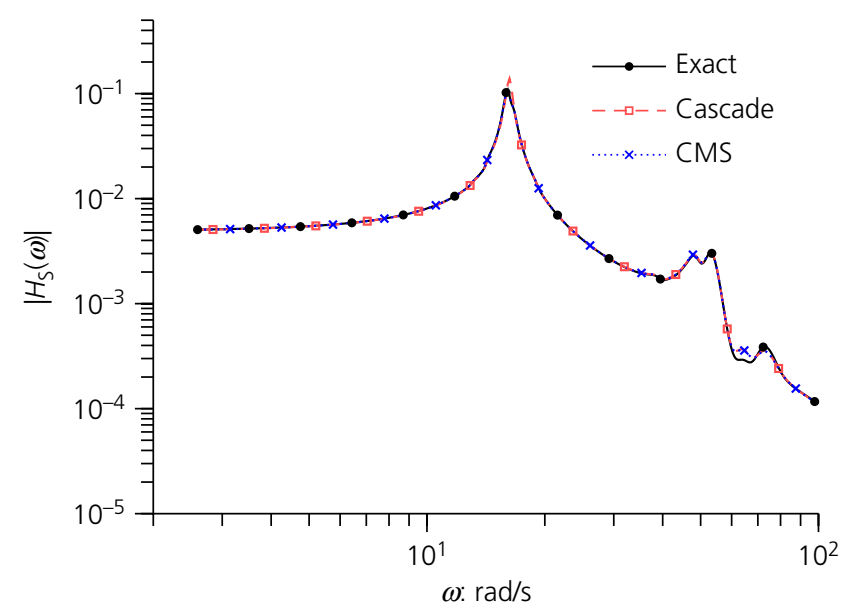

(a)

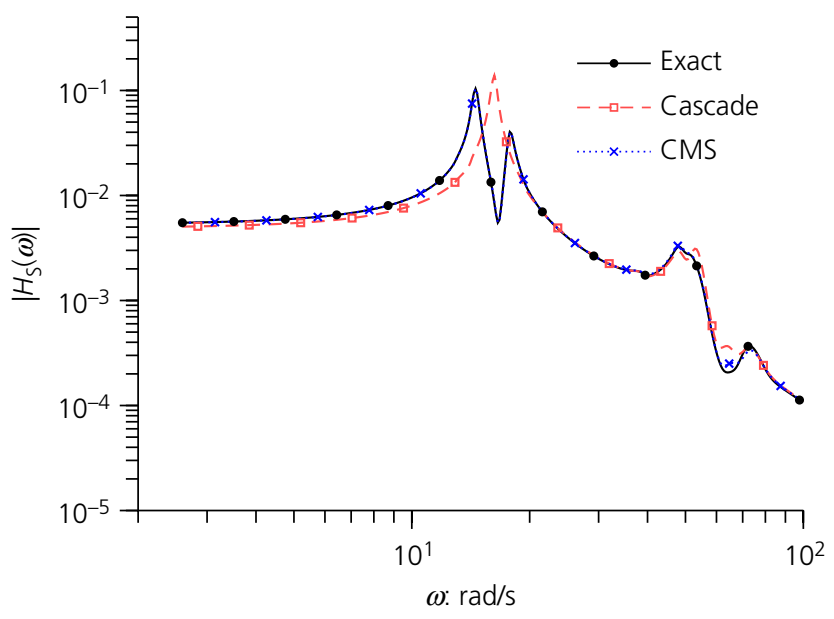

(b)

Figure 2. FRFs for cascade and CMS on a light (a) and heavy (b) S system where the $\mathrm{P}-\mathrm{S}$ dynamic interaction is neglected (dashed line). Two cases of light $(\mu=0 \cdot 003$, Figure 2(a)) and heavy $(\mu=0 \cdot 10$, Figure 2(b)) S attachment are considered.

It is evident that for the light S piping, both the CMS and cascade approximation closely match the exact response. Conversely, when the mass of the $\mathrm{S}$ subsystem increases, the CMS still gives accurate predictions, with only minor inconsistencies observed in the high-frequency range $(\omega>65 \mathrm{rad} / \mathrm{s})$, while the response predicted by the cascade approximation also introduces a significant inaccuracy in the low-frequency range and the fundamental frequency of vibration is overestimated.

The accuracy and computational efficiency of the CMS was also confirmed with time domain analyses, which demonstrated an average reduction of $43 \%$ in the execution time compared with the full combined dynamic system in the geometrical space.

Given the good level of fidelity and efficiency exhibited by the CMS, this model was used to investigate how irregularities in the $\mathrm{P}$ frame affect the coupled dynamic response of the $\mathrm{P}-\mathrm{S}$ system, as detailed in the following subsection.

\subsection{Effects of irregularities in the P structure}

\subsubsection{Frequency response}

Figure 3 shows the FRFs for the two scenarios under investigation (i.e. mass irregularity in elevation and stiffness irregularity in plan), in which the thick solid curves denote the reference case, without irregularities, and the curves for the higher level of irregularity are denoted with the thick dashed line, namely $\mu=6$ for the mass irregularity (Figures 3(a)-3(d)) and $\kappa=1 \cdot 2$ for the stiffness irregularity (Figures 3(e) and 3(f)).

Overall, the effect of irregularity is more evident on the highfrequency range, in which the different combinations of higher modes of vibration cause large fluctuations in both $\mathrm{P}$ and $\mathrm{S}$ subsystems, although the variations in the $\mathrm{S}$ attachment appear to be less ordered, requiring a $\mathrm{P}-\mathrm{S}$ coupled dynamic analysis to quantify them.

\subsubsection{Displacement EDPs for mass irregularities}

Figure 4 summarises the results obtained for the combined $\mathrm{P}-\mathrm{S}$ system under investigation when dynamic analysis is carried out in the time domain and the mass irregularity is varied at different locations. The figures present the results for a given accelerogram (El Centro 1940 in Figures 4(a) and 4(b), Erzincan 1992 in Figures 4(c) and 4(d) and Irpinia 1980 in Figures 4(e) and 4(f)), all applied in the $x$ direction. in Figures 4(a), 4(c) and 4(e) show the maximum responses in the $\mathrm{P}$ frame (i.e. the maximum $x$ displacements of point $R_{\mathrm{P}}$ ) and Figures 4(b), 4(d) and 4(f) show the maximum responses in the $\mathrm{S}$ piping (i.e. the maximum $x$ displacements of point $R_{\mathrm{S}}$, 


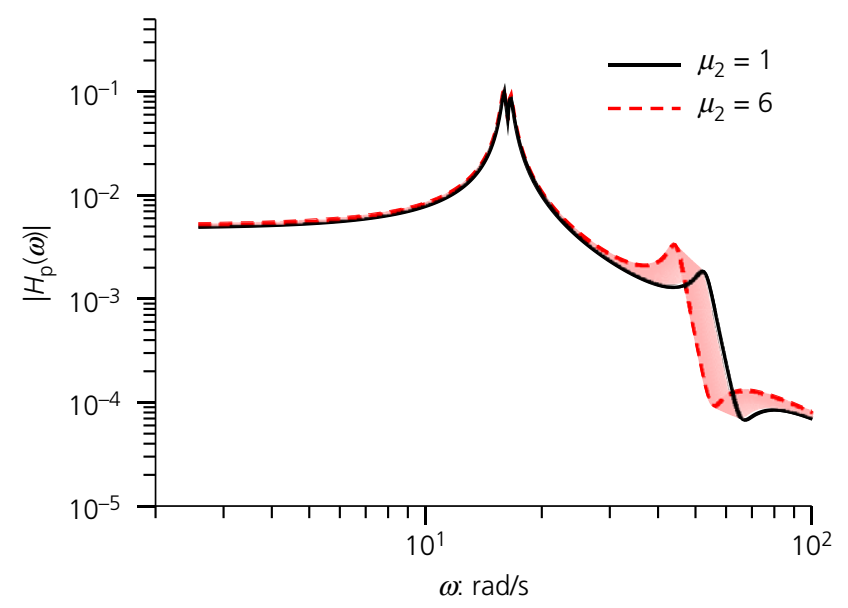

(a)

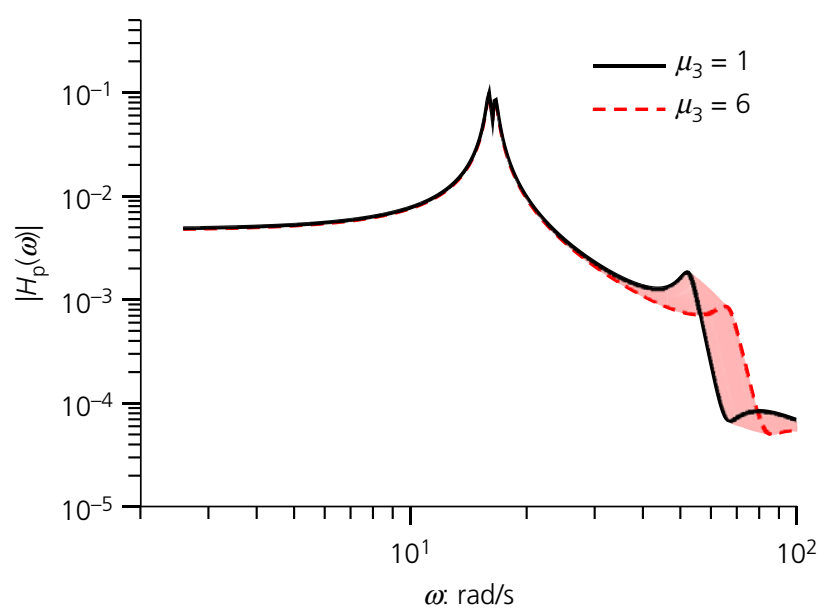

(c)

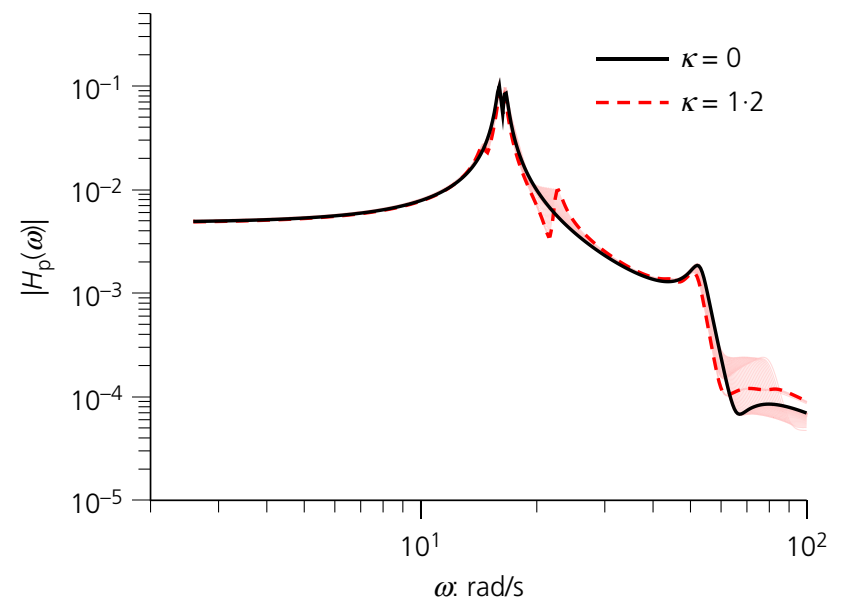

(e)

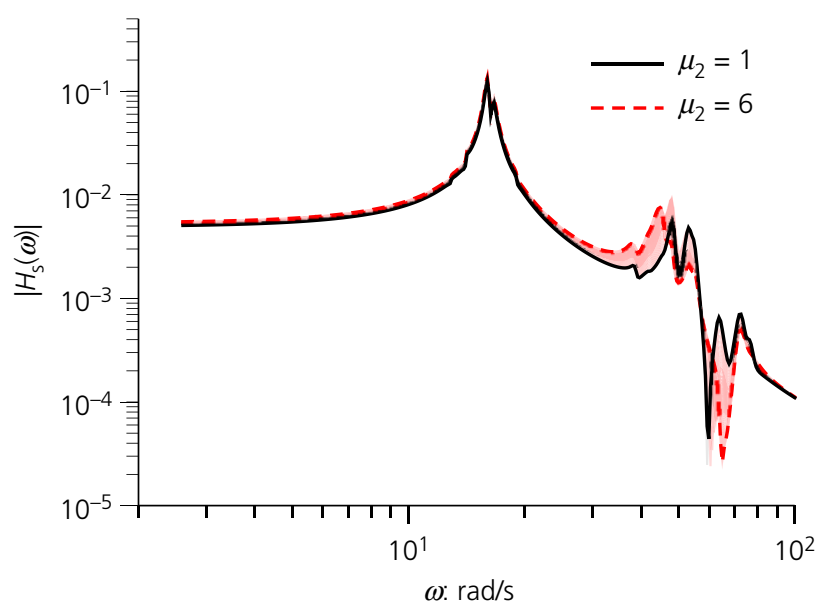

(b)

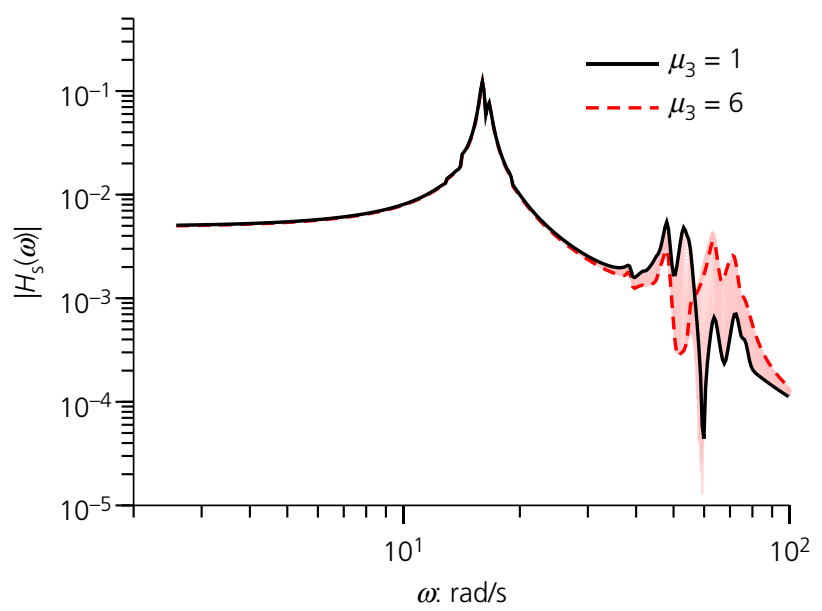

(d)

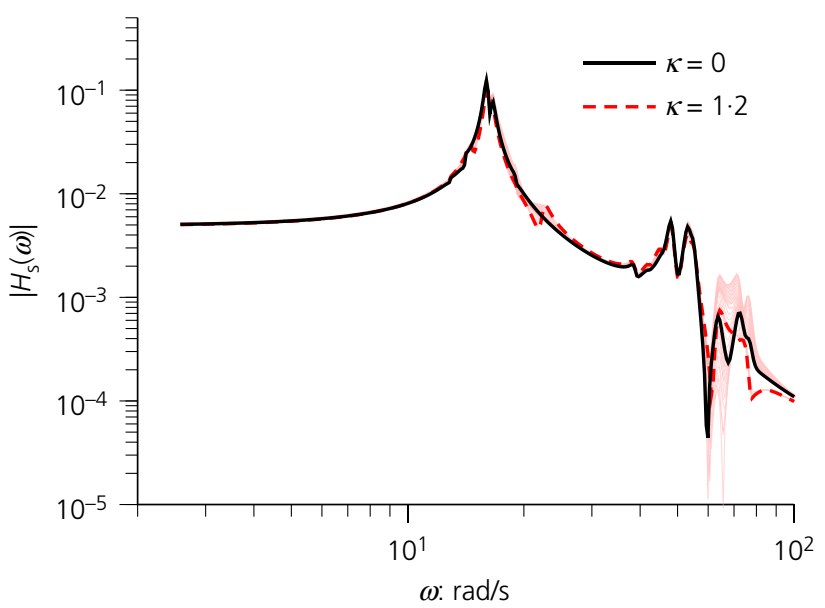

(f)

Figure 3. FRFs for vertical mass irregularity on second storey ((a) and (b)) and third storey ((c) and (d)), and in-plan stiffness irregularity ((e) and (f)) quantified on P (left) and S (right) 


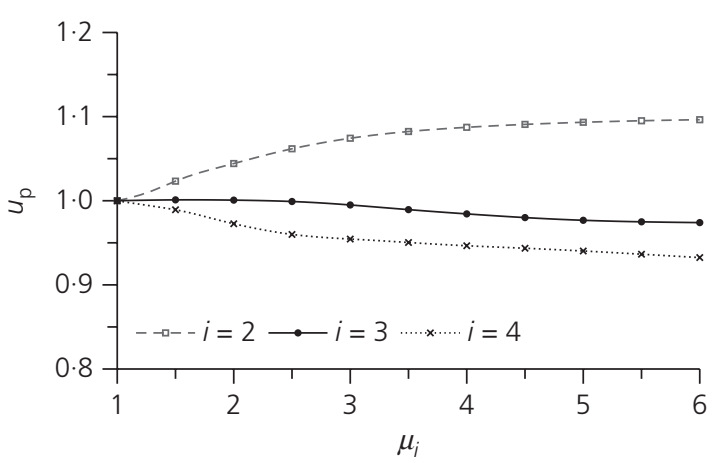

(a)

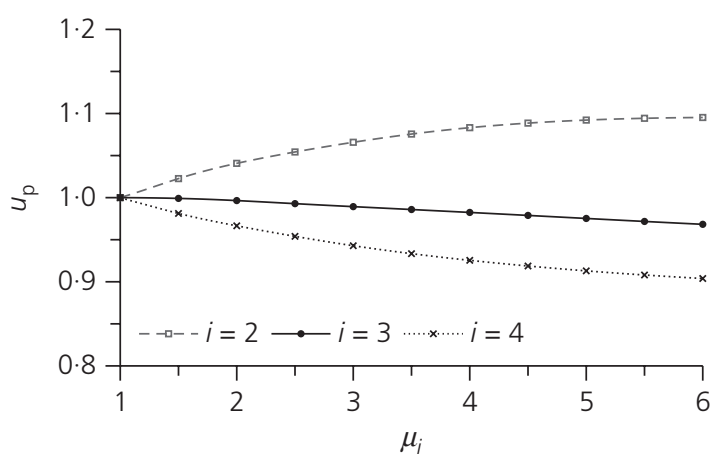

(c)

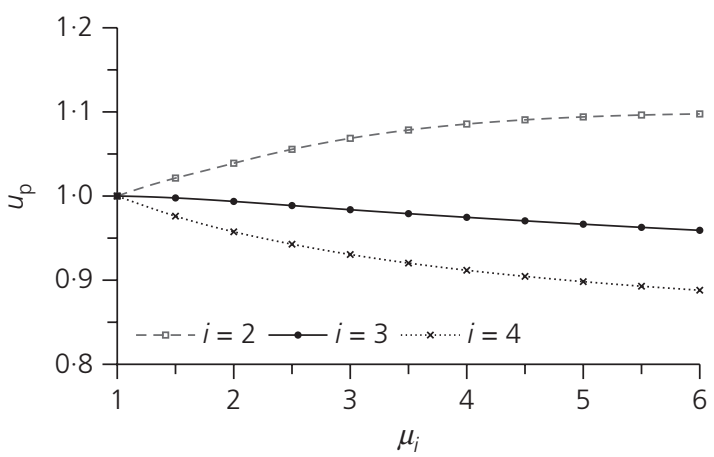

(e)

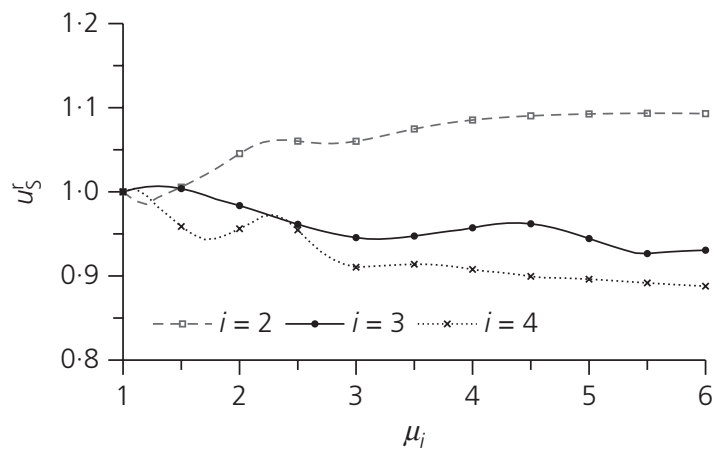

(b)

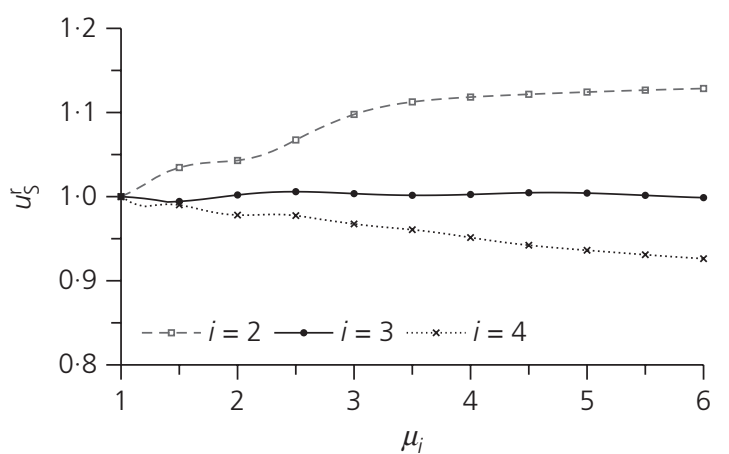

(d)

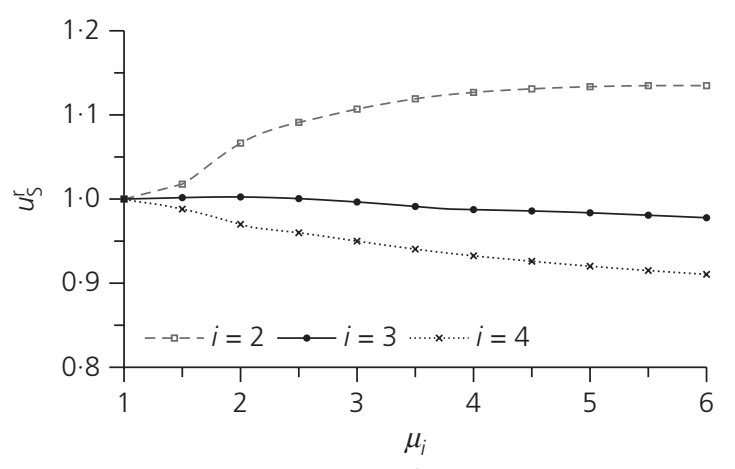

(f)

Figure 4. Displacement EDPs due to vertical mass irregularity at various storeys for El Centro ((a) and (b)), Erzincan ((c) and (d)) and Irpinia ((e) and (f)) earthquakes, quantified on P (left) and S (right), in the $x$ direction

relative to the $\mathrm{P}$ frame); in both cases, the results are normalised with respect to the corresponding maxima observed for the regular $\mathrm{P}$ frame $\left(\mu_{i}=1\right)$.

As shown, the mass irregularity tends to cause an overall increase of $u_{\mathrm{P}}$ at lower storeys $(i=2)$ with the effect reversed at higher elevations $(i=4)$, also evident in all the three accelerograms and consistent with the FRFs (Figures 3(a)-3(d)). Similar trends can also be seen for $u_{\mathrm{S}}$. While the details of the various curves inevitably depend on the time-frequency distribution of the energy content for each accelerogram, it is interesting to note that the EDP of the S piping appears to show similar sensitivities to the $\mathrm{P}$ frame to the presence of mass irregularity, suggesting that any regularity criterion assumed for the $\mathrm{P}$ structure could also be used for the $\mathrm{S}$ subsystems. In this respect, however, the $150 \%$ and $200 \%$ thresholds set for $\mu_{i}$ by various codes of practice appear to be quite arbitrary and not necessarily associated with a significant change in the seismic response of the structure.

Overall, it appears that the relative displacements in the $\mathrm{P}$ structure could be used for assessing the expected performance of light drift-sensitive S subsystems, without resorting to sophisticated methods of analysis, such as the CMS used in this 
paper. Effectively, the variation in amplitude of the motion due to irregularities in the $\mathrm{P}$ frame results in a similar variation in the $\mathrm{S}$ piping.

\subsubsection{Displacement EDPs for stiffness irregularities}

The effects of stiffness irregularities in plan are presented in Figure 5, for both $\mathrm{P}$ and $\mathrm{S}$ components, using the EDPs $u_{\mathrm{P}}$ and $u_{\mathrm{S}}$ in the two orthogonal directions $x$ (solid lines, parallel to the direction of the earthquake) and $y$ (dashed lines, orthogonal to it). To allow for easier comparison, both responses along $x$ and $y$ for a given accelerogram are normalised with

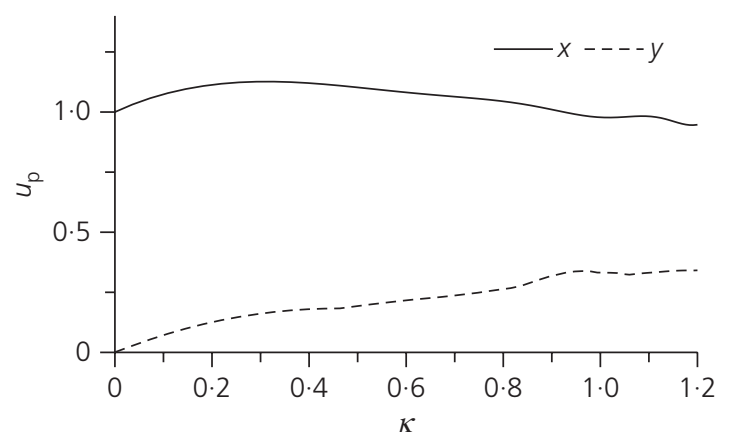

(a)

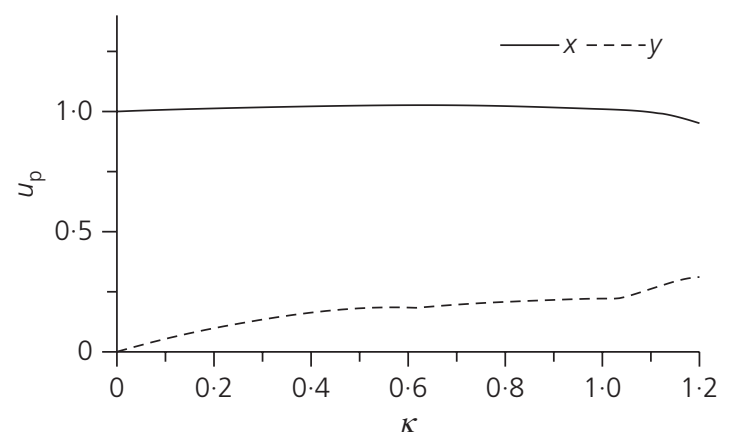

(c)

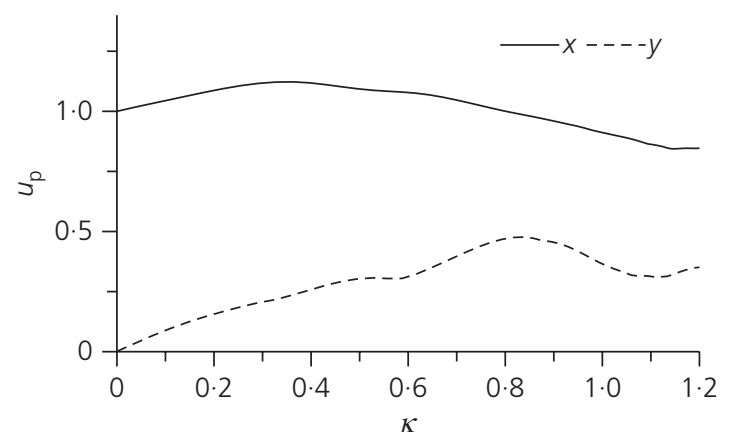

(e)

Figure 5. Displacement EDPs due to stiffness irregularity in-plan, for El Centro ((a) and (b)), Erzincan ((c) and (d)) and Irpinia ((e) and (f)) earthquakes, quantified on $\mathrm{P}$ (left) and S (right), in the $x$ and $y$ directions respect to the response of each submodel in the $x$ direction when the $\mathrm{P}$ frame is regular (i.e. for $\kappa=0$ ).

In this circumstance, the $\mathrm{P}$ and $\mathrm{S}$ components appear to have similar levels of sensitivity to the structural irregularity. As expected, the induced torsional vibration in the $\mathrm{P}$ frame means that the dynamic response orthogonal to the direction of the earthquake increases with the level of stiffness irregularity, with a maximum value of $u_{\mathrm{P} y}=0.35$ (i.e. $35 \%$ of the corresponding response of the regular frame in the $x$ direction) for the Irpinia 1980 record (Figure 5(e)).

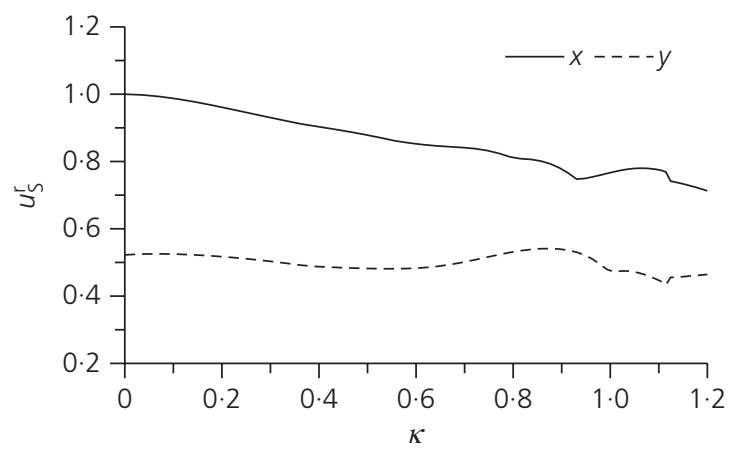

(b)

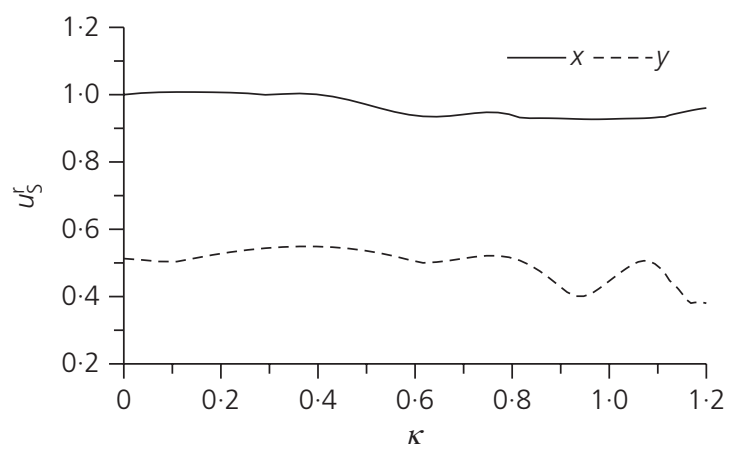

(d)

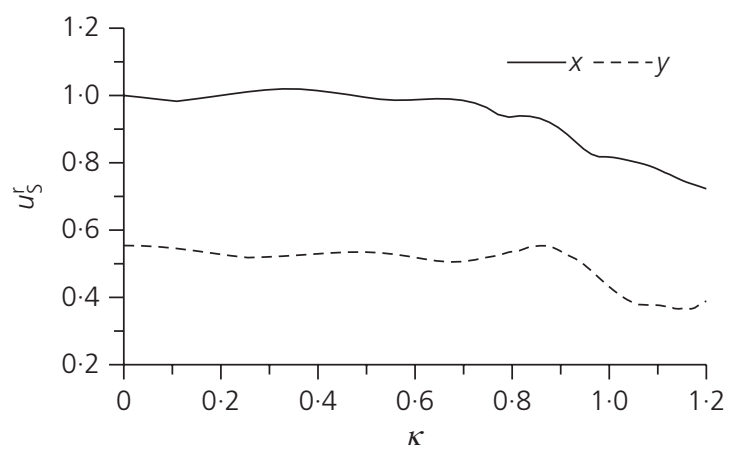

(f) 
Given the unsymmetrical geometry of the $\mathrm{S}$ piping (see Figure 1(b)), the point $R_{\mathrm{S}}$ used to evaluate the EDPs always experiences both $x$ and $y$ vibrations even for $\kappa=0$ (regular $\mathrm{P}$ frame), in which case $u_{\mathrm{S} y}$ is about half of $u_{\mathrm{S} x}$ (Figures $5(\mathrm{~b})$, 5(d) and 5(f)).

Interestingly, for El Centro 1940 (Figures 5(a) and 5(b)), the maximum response of the $\mathrm{S}$ piping in the $y$ direction can be as large as $u_{\mathrm{S} y}=0 \cdot 53$, becoming comparable to the maximum response in the direction of the ground motion, highlighting the importance that irregularities in plan can have not only

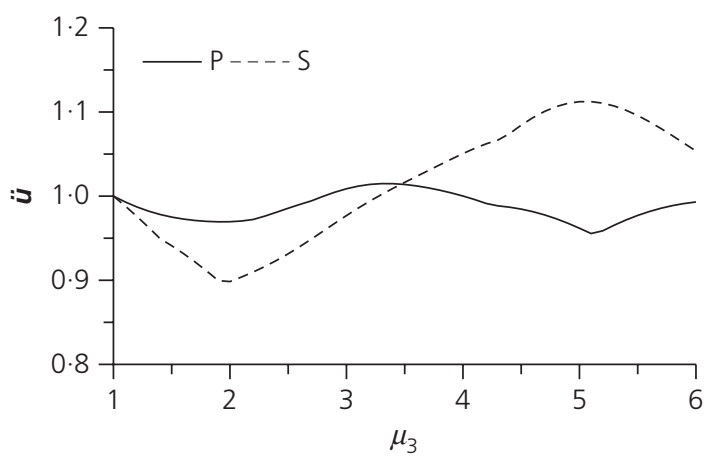

(a)

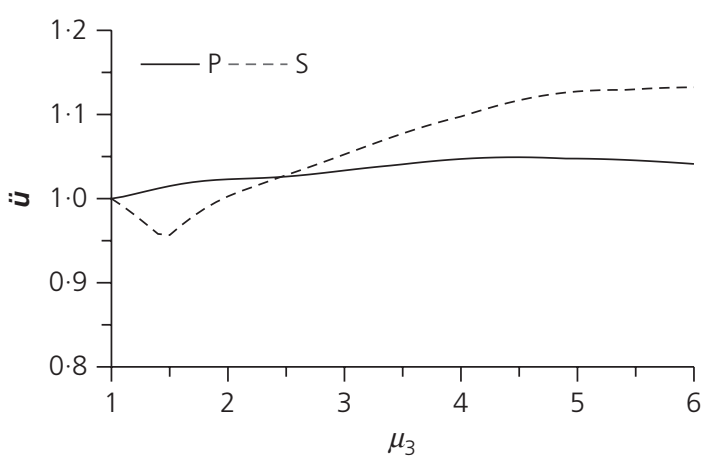

(c)

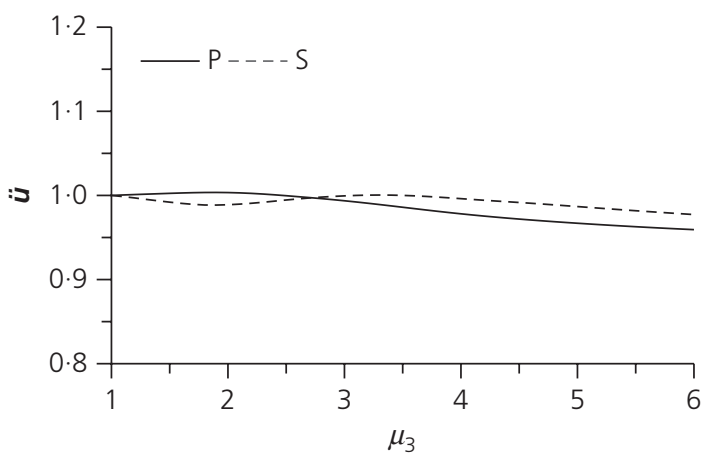

(e)

Figure 6. Acceleration EDPs of $\mathrm{P}$ and $\mathrm{S}$ subsystems for El Centro ((a) and (b)), Erzincan ((c) and (d)) and Irpinia ((e) and ( $f)$ ) earthquakes with respect to vertical mass (left) and in-plan stiffness (right) irregularities on the P load-bearing structural elements, but also on $\mathrm{S}$ subsystems. This also suggests that, when drift-sensitive nonstructural attachments are required for the serviceability of buildings with irregular plans, any torsional movement should be minimised if possible, and the effects on the $\mathrm{S}$ components should be quantified at the design stage.

\subsubsection{Acceleration EDPs for irregular frames}

Figure 6 presents the maximum absolute accelerations of both $\mathrm{P}$ and $\mathrm{S}$ components due to the presence of mass irregularity

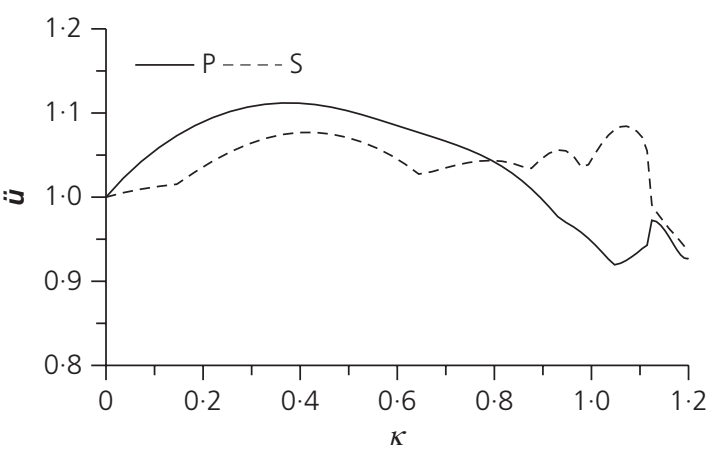

(b)

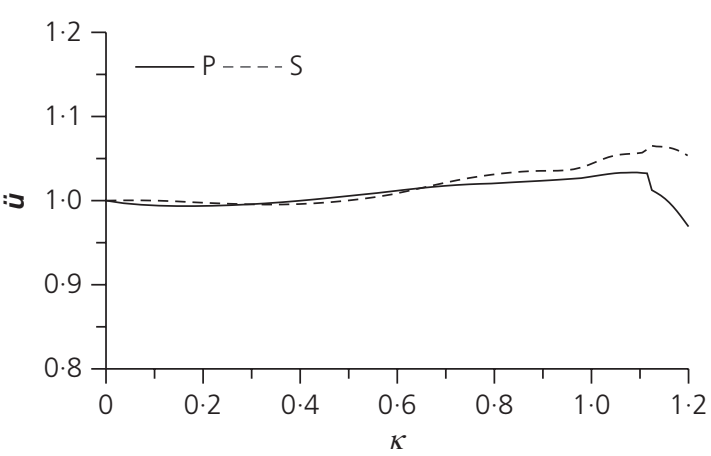

(d)

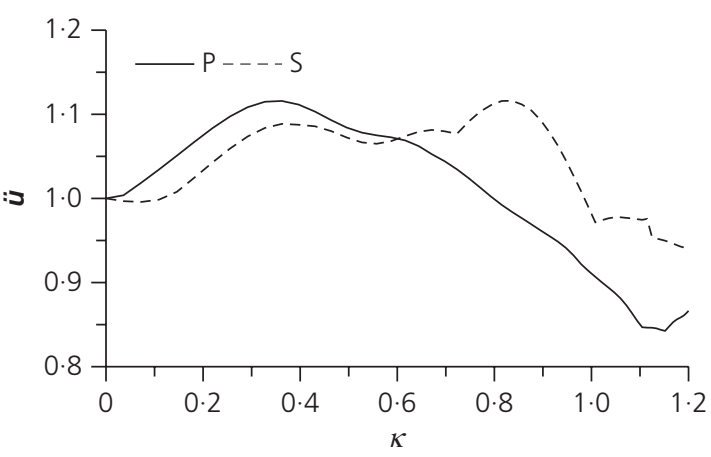

(f) 
at the third floor $(i=3$, Figures 6(a), 6(c) and 6(e)) and stiffness asymmetry (Figures 6(b), 6(d) and 6(f)).

While in the case of the Erzincan 1992 and Irpinia 1980 earthquakes, the curves for the two subsystems are very close for mass and stiffness irregularities, respectively (Figures 6(d) and 6(e)), this is not always true and, indeed, very different trends are observed in some cases for the $\mathrm{P}$ frame and the $\mathrm{S}$ attachment.

Additionally, the sensitivity to structural irregularities in terms of absolute accelerations increases for both $\mathrm{P}$ and $\mathrm{S}$ elements in comparison with the relative displacements, mainly because the first modes of vibration of the $\mathrm{P}$ structure, which are those primarily affected by irregularities in plan and elevation, contribute more to the absolute accelerations than to the relative displacements.

Although the limited number of earthquake records and the specific features of the case study do not allow general conclusions to be drawn, it appears that the enhanced sensitivity and irregular seismic response would require use of the CMS to assess the expected performance of acceleration-sensitive secondary systems.

\section{Conclusions}

A parametric study was carried out in which a convenient variant of the component-mode synthesis method (CMS) was exploited with the aim of assessing the seismic response of a secondary (S) piping subsystem multi-connected to a primary (P) multi-storey moment resisting frame exhibiting various degrees of irregularities. Within the limitation of the primarysecondary $(\mathrm{P}-\mathrm{S})$ case study and the small number of accelerograms considered, the numerical results obtained support the following conclusions.

- The CMS is an efficient alternative to the cascade approximation, as the dynamic interaction between the two components is accounted for, therefore improving accuracy in the evaluation of the seismic response. Moreover, since the modes of vibration of the $\mathrm{P}$ structure and $\mathrm{S}$ subsystem are used, the computational effort is less than the full combined model in the geometrical space. A further practical advantage of the CMS is that $\mathrm{P}$ and $\mathrm{S}$ components can be designed independently by different teams, which only need to exchange the relevant modal information to check the effects of the dynamic interaction.

- For the chosen case study, mass irregularities at lower elevations tend to increase the displacements of both the $\mathrm{P}$ frame and S piping, while opposite effects are noted at higher storeys. The two subsystems were found to exhibit similar levels of sensitivity to irregularity, and the regularity thresholds set by various codes of practice for the mass in elevation (i.e. $150 \%$ or $200 \%$ between adjacent storeys) are not associated with any significant change qualitative or quantitative - in the seismic response of the structure, meaning that further research is needed to establish more representative regularity conditions.

- Stiffness irregularity in plan, which induces torsional effects, does not always increase the relative displacements in the $\mathrm{P}$ frame, with a comparable level of sensitivity found for the $\mathrm{S}$ piping.

- The absolute accelerations in $\mathrm{P}$ and $\mathrm{S}$ components reveal increased sensitivity to structural irregularities in comparison with the relative displacements.

The above observations suggest that the relative displacements evaluated for the $\mathrm{P}$ structure can often provide a good basis to assess the performance of light drift-sensitive $\mathrm{S}$ attachments, without requiring a coupled dynamic analysis, while higher sensitivity and more irregular seismic responses would benefit from the use of the CMS for $\mathrm{S}$ acceleration-sensitive subsystems.

Future investigations will be carried out to further improve the CMS via Mam and DyMam modal corrections (Palmeri and Lombardo, 2011), increasing the accuracy when a reduced number of modes is retained for each of the two components. Additionally, the proposed formulation will be extended to account for uncertainties in the mass, stiffness and damping of both $\mathrm{P}$ and $\mathrm{S}$ components, as well as the random characteristics of ground shaking.

\section{REFERENCES}

ASCE (American Society of Civil Engineers) (2010) ASCE 7-10: Minimum design loads for buildings and other structures. American Society of Civil Engineers, Reston, VA, USA.

Aydin K (2007) Evaluation of Turkish seismic code for mass irregular buildings. Indian Journal of Engineering \& Materials Sciences 14(3): 220-234.

Biondi B and Muscolino G (2000) Component-mode synthesis method variants in the dynamics of coupled structures. Meccanica 35(1): 17-38.

BIS (Bureau of Indian Standards) (2002) IS 1983 (Part 1): Criteria for earthquake resistant design of structures, part 1 - general provisions and buildings (fifth revision). Bureau of Indian Standards, New Delhi, India.

BSI (2004) BS EN 1998-1:2004: Eurocode 8: design of structures for earthquake resistance - part 1: general rules, seismic actions and rules for buildings. British Standards Institution, London, UK.

Cecini D and Palmeri A (2015) Spectrum-compatible accelerograms with harmonic wavelets. Computers and Structures 147: 26-35.

Choi BJ (2004) Hysteretic energy response of steel momentresisting frames with vertical mass irregularities. The Structural Design of Tall and Special Buildings 13(2): 123-144. 
CSI (Computers \& Structures, Inc.) (2007) Sap2000. Release 15.2.1. Computers \& Structures, Inc., Walnut Creek, CA, USA.

Das S and Nau JM (2003) Seismic design aspects of vertically irregular reinforced concrete buildings. Earthquake Spectra 19(3): 455-477.

fib (International Federation for Structural Concrete) (2012) Probabilistic Performance-based Seismic Design. International Federation for Structural Concrete, Lausanne, Switzerland, Bulletin 68.

Gokdemir H, Ozbasaran H, Dogan M, Unluoglu E and Albayrak U (2013) Effects of torsional irregularity to structures during earthquakes. Engineering Failure Analysis 35: 713-717.

Hurty WC (1960) Vibrations of structural systems by component-mode synthesis. Journal of Engineering Mechanics Division 86(4): 51-70.

ICBO (International Conference of Building Officials) (1997) Uniform Building Code - Volume 2. International Conference of Building Officials, Whittier, CA, USA.

Kumar BG, Gornale A and Mubashir A (2012) Seismic performance evaluation of RC-framed buildings - an approach to torsionally asymmetric buildings. IOSR Journal of Engineering 2(7): 1-12.

Lavan O and De Stefano M (2013) Seismic behaviour and design of irregular and complex civil structures. Geotechnical, Geological and Earthquake Engineering 24: 47-58.

Muscolino G and Palmeri A (2007) An earthquake response spectrum method for linear light secondary substructures. ISET Journal of Earthquake Technology 44(1): 193-211.

Muscolino G and Palmeri A (2013) Seismic analysis of light secondary substructures via an extended response spectrum method. New Trends in Seismic Design of Structures (Lagaros ND, Tsompanakis Y and Papadrakakis M (eds)). Saxe-Coburg Publications, Kippen, UK, pp. 289-321. NBCC (2010) NRCC 53301: National building code of Canada: volume 1. National Research Council of Canada, Ottawa, ON, Canada.

Ozmen G (2004) Excessive torsional irregularity in multi-storey structures. Teknik Dergi Digest 15(1): 3331-3144.

Palmeri A and Lombardo M (2011) A new modal correction method for linear structures subjected to deterministic and random loadings. Computers \& Structures 89(11-12): 844-854.

Shahrooz BM and Moehle JP (1990) Seismic response and design of setback buildings. Journal of Structural Engineering 116(5): 1423-1439.

Tezcan SS and Alhan C (2001) Parametric analysis of irregular structures under seismic loading according to the new Turkish earthquake code. Engineering Structures 23(6): 600-609.

TMWI (The MathWorks, Inc.) (2013) Matlab. Release 8.2. The MathWorks, Inc., Natick, MA, USA.

Valmundsson EV and Nau JM (1997) Seismic response of building frames with vertical structural irregularities. Journal of Structural Engineering 123(1): 30-41.

Varadharajan S, Sehgal VK and Saini B (2014) Seismic response of multistory reinforced concrete frame with vertical mass and stiffness irregularities. The Structural Design of Tall and Special Buildings 23(5): 362-389.

Villaverde R (2009) Fundamental Concepts of Earthquake Engineering. CRC Press, Boca Raton, FL, USA.

Wood SL (1992) Seismic response of R/C frames with irregular profiles. Journal of Structural Engineering 118(2): 545-566.

\section{WHAT DO YOU THINK?}

To discuss this paper, please email up to 500 words to the editor at journals@ice.org.uk. Your contribution will be forwarded to the author(s) for a reply and, if considered appropriate by the editorial panel, will be published as discussion in a future issue of the journal.

Proceedings journals rely entirely on contributions sent in by civil engineering professionals, academics and students. Papers should be 2000-5000 words long (briefing papers should be 1000-2000 words long), with adequate illustrations and references. You can submit your paper online via www.icevirtuallibrary.com/content/journals, where you will also find detailed author guidelines. 